\title{
ФОРМИРОВАНИЕ ТЕХНОЛОГИЙ ВЗАИМОДЕЙСТВИЯ АГЕНТОВ НЕФТЕСЕРВИСНОГО РЫНКА С ПРИМЕНЕНИЕМ ЦИФРОВЫХ ТЕХНОЛОГИЙ
}

\author{
(c) 2020 Томазова Олеся Владимировна \\ доцент, кафедра «Экономика промышленности и производственный менеджмент» \\ Самарский государственный технический университет, Россия, Самара \\ E-mail: ovtom@mail.ru
}

Актуальность исследования обусловлена тем, что в современном обществе, основанном на знании, применение цифровых технологий должно стать нормой при взаимодействии агентов российского рынка нефтесервиса. В связи с этим, данная статья направлена на формирование технологий взаимодействия агентов нефтесервисного рынка при выполнении работ по восстановлению и реновации оборудования. Ведущим подходом к исследованию данной проблемы являются системный и комплексный анализ, а также метод экономико-математического моделирования, применение которых позволило автору целостно и объективно построить модель эффективного взаимодействия агентов рынка нефтесервиса с применением цифровых технологий.

Материалы статьи представляют практическую ценность для научных работников и специалистов, занимающихся проблемами применения современных технологий взаимодействия агентов нефтесервисного рынка, руководителей предприятий нефтегазового комплекса, передающих на аутсорсинг отдельные бизнес-процессы восстановления и реновации оборудования.

Ключевые слова: агенты, алгоритмы взаимодействия, бизнес-процессы, восстановление и реновация оборудования, рынок нефтесервиса, цифровизация.

Проблема применения цифровых технологий при управлении восстановлением и реновацией оборудования предприятий нефтегазового комплекса является актуальным направлением исследования.

В Послании Федеральному Собранию в 2017 году Президент РФ В.В.Путин поставил задачу подготовки специальной программы создания цифровой экономики, в результате чего в настоящее время разработана и начала исполняться Программа «Цифровая экономика РФ» [2].

Отдельные российские нефтяные компании уже внедряют в практику своей деятельности цифровые технологии, но они, в основном, связаны с цифровизацией основных бизнеспроцессов. Автор считает, что для обеспечения бесперебойной работы оборудования предприятия нефтегазового сектора должны прибегать к специализированным нефтесервисным компаниям, которые осуществляют такие важные для работы нефтяного оборудования вспомогательные бизнес-процессы, как восстановление и реновация оборудования. Процессы взаимодействия между заказчиком и подрядчиком этих вспомогательных услуг также нуждаются в цифровизации. Поэтому целью данного исследования является разработка взаимодействия агентов нефтесервисного рынка с помощью цифровых технологий, а его задачами разработка теоретико-методических положений и практических рекомендаций их реализации.

Применение цифровых технологий в бизнеспроцессах всей технологической цепочки предприятий нефтегазового комплекса России имеют свои особенности.

1. Бизнес-процесс «Поиск и разведка»:

- высокочувствительные датчики небольшого размера, позволяющие инженерам на основе анализа данных лучше контролировать параметры разработки пласта [3].

- расширенная интеграция данных в реальном времени от полевых датчиков (старых и новых) с моделью коллектора обеспечивает более надежное четырехмерное моделирование и, в свою очередь, более динамичное управление пластом [4].

2. Бизнес-процесс «Разработка и обустройство»:

- модуль SAP PM (ТОРО) дает возможность осуществлять прогнозирование и эффективное планирование техобслуживания и ремонтов оборудования, контролировать выполнение ремонтных работ, управлять затратами на закупки материалов и запчастей, автоматически созда- 
вать аналитические и справочные отчеты, проводить анализ эффективности использования ресурсов [5].

3. Бизнес-процесс «Нефтедобыча»:

- “цифровые двойники” обеспечивают интерактивное трехмерное моделирование. Его применение способствует удаленному маневрированию нефтяных платформ, когда отсутствует возможность добраться до буровой установки. Используя описываемую цифровую технологию у инженеров, появилась возможность работать удаленно [6].

4. Бизнес-процесс «Транспорт»:

- SCADA Infinity - система управления режимом работы трубопровода предназначена для автоматизированного запуска и останова трубопровода, изменения текущего режима перекачки, автоматического поддержания заданного режима перекачки и автоматических защит трубопровода при возникновении аварийных ситуаций [7].

5. Бизнес-процесс «Переработка»:

- программные продукты для установок по переработки углеводородов.

В процессе исследования были использованы следующие методы:

- метод системного анализа, позволивший при постановке проблемы исследовать функциональное взаимодействие агентов нефтесервисного рынка, а также всех отделов и служб предприятий нефтегазового комплекса, отвечающих за восстановление оборудования при внедрении моделей и алгоритмов цифровизации организации его ремонта и постремонтного обслуживания;

- метод экономико-математического моделирования, позволяющий обосновать модель принятия управленческого решения по вопросам взаимодействия агентов сервисного рынка при восстановлении оборудования, при планировании ремонтов и модернизации, и выборе способа их осуществления с применением цифровых технологий;

- концепция рационального поведения рыночных субъектов, позволяющая делать выводы об оптимальности выбора пакета цифровых продуктов и метода цифровизации при восстановлении оборудования, повышении срока его службы, качества ремонтных работ.

Методической и практической базой исследования являются лучшие практики зарубежных нефтесервисных предприятий.
Опытно-экспериментальной базой исследования являются российские предприятия нефтегазового комплекса.

С этой целью в данном научном труде разработана модель взаимодействия агентов нефтесервисного рынка с помощью цифровых технологий при осуществлении работ по восстановлению и реновации оборудования предприятий нефтегазового комплекса.

Для решения поставленной задачи автор:

1. обосновал актуальность применения моделей и цифровых технологий при осуществлении вспомогательных операций восстановления и реновации в нефтегазовом комплексе;

2. разработал экономико-математические модели выбора сервисной организации для передачи на аутсорсинг процессов восстановления и для реновации оборудования предприятий нефтегазового комплекса.

1. Обоснование актуальности применения моделей и цифровых технологий при осуществлении вспомогательных операций объясняется следующими обстоятельствами:

- необходимостью решения системных проблем поддержания материально-технической базы российских предприятий нефтегазового комплекса: износ оборудования, отсутствие адресной поддержки от государства и инновационных технологий, непрозрачность отношений между заказчиком и исполнителем, конкуренция, которые сформировались достаточно давно и их решение требует кардинально нового подхода;

- насущной потребностью цифровизации процессов взаимодействия агентов российского нефтесервисного рынка. Следует отметить, что процессы автоматизации и информатизации основных и вспомогательных бизнес-процессов, связанных с функционированием основных средств предприятий нефтегазового комплекса начался еще задолго до становления рыночных отношений, и руководство еще тогда существовавших нефтегазодобывающих управлений, опиралось на полученные данные с центральной инженерно-технологической службы, принимало решение о дальнейшей судьбе основных фондов.

Анализируя вышеперечисленное, можно увидеть, что цифровые технологии в нефтегазовой отрасли особенно коснулась бизнеспроцессов разведки, разработки и добычи. Данные процессы получили свое выражение в виде «умных скважин» и «цифровых месторождений». 
На этом фоне цифровизация бизнес-процессов восстановления и реновации оборудования реализована, на сегодняшний день фрагментарно, в виде программных продуктов для сбора данных о работоспособности средств труда. Наиболее востребованными зарубежными ЕАМ-системами в России считаются SAP PM, IBM Maхimo, среди отечественных наиболее известны - Галактика TOPO, TRIM, 1C: Предприятие 8 «Управление ремонтом и обслуживанием оборудования» [1].

2. Автором разработаны экономико-математическая модель выбора сервисной организации для передачи процессов восстановления и модель обоснования реновации оборудования предприятий нефтегазового комплекса.

С помощью разработанных экономико- математических моделей можно осуществить оптимальное взаимодействия между агентами нефтесервисного рынка в области выбора сервисной компании для передачи на аутсорсинг вспомогательных операции по восстановлению оборудования и выбор варианта реновации оборудования.

Математическая модель выбора сервисной компании позволит менеджменту нефтегазовых компаний осуществить выбор наилучшего посредника для эффективной организации вспомогательных бизнес-процессов по ремонту и техническому обслуживанию оборудования по критерию минимизации цены на оказываемые услуги.

$Ц_{\text {усл } \rightarrow \min }$

Ограничения модели:

T - срок работы на рынке нефтесервисных услуг $\geqslant 10$ лет;

$\mathrm{Q}_{\mathrm{r}}-$ количество сертифицированных бизнес-процессов ремонта $\geqslant 4$;

$\mathrm{Q}_{\mathrm{M}}-$ количество сертифицированных бизнес-процессов модернизации $\geqslant 3$;

$\mathrm{t}_{\mathrm{r}}$ - время безотказной работы оборудования после мелкого и среднего ремонта $\geqslant 2$ года;

$\mathrm{t}_{\mathrm{K}}$ - время безотказной работы оборудования после капитального ремонта $\geqslant 5$ лет;

$\mathrm{t}_{\mathrm{M}}$ - время безотказной работы оборудования после модернизации $\geqslant 3$ года;

В случае реновации оборудования предлагаем модель обоснования выбора варианта реновации, при котором сервисная компания может быть поставщиком.

Экономико-математическая модель обоснования выбора варианта реновации оборудования реализуется по критерию минимизация цены на закупаемое оборудование.

$Ц_{\text {зак.обор } \rightarrow \min }$

Ограничения модели:

$\mathrm{T}-$ срок работы оборудования $\geqslant 10$ лет;

$\mathrm{n}$ - количество инновационных технологических операций, которые можно выполнить на данном оборудовании согласно применяемости к конструкции производимого изделия и видов обработки (деталей, частей изделия), $\mathrm{n} \geqslant 1, \ldots, \mathrm{N}$; $\mathrm{N}$ максимально-возможное число операций, необходимое для изготовления деталей, узлов, изделий запланированной номенклатуры согласно специализации рабочего места (участка, цеха).

Основное препятствие цифровой трансформации для российского нефтяного сервиса объясняется высокой зависимостью от иностранных технологий на фоне действия санкций.

В российском нефтяном бизнесе уже давно имеются все условия для расширения направлений цифровизации основных и вспомогательных бизнес-процессов. Его обусловливает прежде всего, формирование в процессе добычи, переработки, перемещения и реализации нефти и газа больших массивов экономически значимых отраслевых и межотраслевых данных.

Одна из ключевых целей цифровизации в нефтегазовой отрасли связана с ростом межремонтного интервала в два-четыре раза, внедрением новых производственных технологий ремонта и технического обслуживания оборудования предприятий нефтегазового сектора.

На рисунке 1 представлена модель взаимодействия заказчика и подрядчика сервисных услуг в области восстановления и реновации оборудования предприятий нефтегазового комплекса с применением разработанных авторами экономико-математических моделей (далее ЭММ).

Данная модель отражает взаимодействие между заказчиком и подрядчиком. Исследуемое взаимодействие включает разделение на основные бизнес-процессы и вспомогательные по восстановлению и реновации оборудования предприятий нефтегазового комплекса. Также данная модель содержит цифровую технологическую платформу, которая содержит два варианта выбора подрядчика на исполнение работ по восстановлению оборудования и принятие управленческого решения по реновации оборудования. При выборе варианта и при принятии управленческого решения используются экономико-математические модели. 


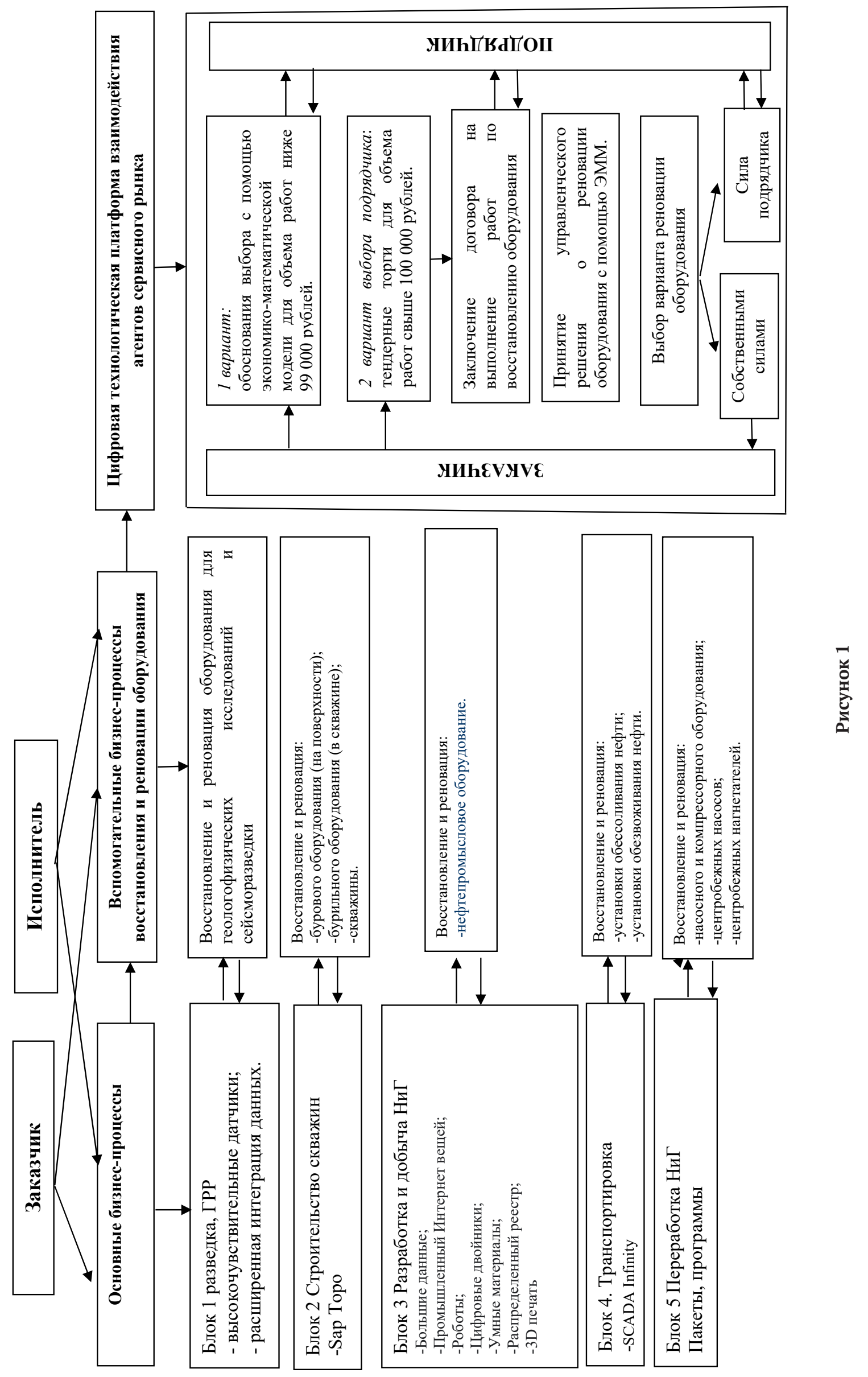


При определении варианта выбора подрядчика на выполнение работ по восстановлению оборудования предприятий нефтегазового комплекса, используется модель выбора сервисной компании по критерию минимизации цены на оказываемые услуги.

При принятии управленческого решения о реновации оборудовании с помощью экономико-математической модели по критерию минимизации цены на закупаемое оборудование, данная модель предусматривает два варианта выбора, первый вариант, когда оборудование приобретается собственными силами заказчика и второй вариант, когда покупка оборудования осуществляется силами подрядчика.

Нефтегазовый комплекс является одним из основных элементов российской экономики, его состояние оказывает существенное влияние на многие сферы экономики РФ.

Участники нефтегазового комплекса полу- чили возможность сделать услуги товаром в бизнесе, создав потенциал для значительного сокращения затрат и повышения эффективности производства.

Большинство предприятий нефтегазового комплекса уже имеют опыт работы с цифровыми технологиями - использование в производственном процессе большое количество датчиков и других устройств для сбора и хранения информации.

Предложенные мероприятия в области развития взаимодействия между агентами нефтесервисного рынка и предприятиями нефтегазового комплекса будут способствовать для достижения инноваций в поиске и разведке; увеличение объемов добычи и нефтеотдачи; прогнозирование утечки продукции и выбросов; повышение производительности труда персонала и уровня эффективности производства.

\section{Библиографический список}

1. Томазова О. В. Цифровизация как инновационный подходк казвитиюсистемыпланово-предупредительных ремонтов предприятий нефтегазового комплекса/Инновационная деятельность. 2018, 4(47), С.47.

2. https://digital.ac.gov.ru (дата обращения 28.12.2020).

3. https://www.forbes.ru/biznes/351129-umnaya-dobycha-pochemu-cifrovye-tehnologii-uderzhat-nizkie-ceny-naneft (дата обращения 29.12.2020).

4. https://www.cisco.com/c/dam/en_us/solutions/industries/energy/docs/OilGasDigitalTransformationWhitePaper. pdf (дата обращения 29.12.2020).

5. http://tls-russia.ru/plant-maintaince-topo/ (дата обращения 30.12.2020).

6. https://nangs.org/news/it/tsifrovizatsiya-neftegazovoy-otrasli-nachalasy-blagodarya-covid-19 (29.12.2020).

7. http://elesy.ru/engineering/solutions/transportirovka-nefti-i-nefteproduktov/sistemy-upravlenija-rezhimomraboty-truboprovoda.aspx 